\title{
Changes in the Health-Related Quality of Life and Weight Status of Children with Overweight or Obesity Aged 7 to 13 Years after Participating in a 10-Week Lifestyle Intervention
}

\author{
Emma van den Eynde, MSc, ${ }^{1,2}$ Roxanna Camfferman, PhD,' Linda R. Putten, BSc, \\ Carry M. Renders, PhD,' Jacob C. Seidell, PhD,' and Jutka Halberstadt, PhD'
}

\section{Abstract}

Background: The aim of the study was to assess changes in the health-related quality of life (HRQOL) and weight status of children with overweight and obesity after participating in a 10-week family-based combined lifestyle group intervention in their community.

Methods: In total, 340 children with overweight or obesity aged between 7 and 13 years, as well as one of their primary caregivers, took part in this intervention, in a real-world setting. The intervention comprised 20 group sessions for a 10-week period, and focused on improving knowledge, attitudes, social support, and self-efficacy in regard to healthy lifestyles. The Pediatric Quality of Life Inventory 4.0 (PedsQL) and Impact of Weight on Quality of Life-Kids (IWQOL-KIDS) questionnaires were used to determine generic and weight-specific HRQOL. Changes in HRQOL and BMI (standard deviation [SDS] of BMI, objectively measured) were tested using a Wilcoxon signed-rank test, Mann-Whitney U test, and paired $t$-test.

Results: Generic quality of life $(Z=-3.58, r=-0.25)$, weight-specific quality of life $(Z=-4.83, r=-0.34)$, and SDS-BMI $(d=0.21)$ were all significantly improved after participating in the 10 -week intervention. The mean attendance rate was $73.74 \%$.

Conclusion: This study demonstrated that participation in the intervention LEFF for children with overweight and obesity was associated with improved generic and weight-specific HRQOL and SDS-BMI.

Keywords: childhood overweight and obesity; family-based combined lifestyle group intervention; health-related quality of life; weight status

\section{Introduction}

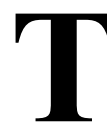
The prevalence of childhood overweight and childhood obesity has increased across the globe in recent decades, ${ }^{1}$ including in the Netherlands. ${ }^{2}$ The high prevalence of overweight and obesity is troubling, because obesity has been shown to negatively impact children's physical health ${ }^{3}$ and psychosocial health. ${ }^{4}$ The more overweight a child has, the greater the health risks. ${ }^{5}$ Indeed, children with higher degrees of overweight have been consistently found to report having a lower healthrelated quality of life (HRQOL). ${ }^{6}$
To improve the health and quality of life for children with overweight or obesity, it is important to design and implement effective interventions. It has been suggested that it is important to use both generic and weight-related quality of life patient-reported outcomes to assess the effectiveness of weight-related interventions. ${ }^{7}$ Improvements in both physical health and HRQOL can lead to many positive outcomes, such as improvements in personal development and in social participation. ${ }^{6,7}$

In the Netherlands, the recommended method for addressing children and adults with overweight and obesity, and, in turn, improving their physical health and HRQOL, is

\footnotetext{
'Department of Health Sciences, Faculty of Science, Vrije Universiteit Amsterdam, Amsterdam Public Health Institute, Amsterdam, the Netherlands. ${ }^{2}$ Department of Pediatric Endocrinology, Erasmus MC, University Medical Center, Rotterdam, the Netherlands.

(C) Emma van den Eynde et al., 2020; Published by Mary Ann Liebert, Inc. This Open Access article is distributed under the terms of the Creative Commons Attribution Noncommercial License (http://creativecommons.org/licenses/by-nc/4.0/) which permits any noncommercial use, distribution, and reproduction in any medium, provided the original author(s) and the source are credited.
} 
a combined lifestyle intervention. ${ }^{7}$ This intervention addresses a combination of the following three components: improvement of diet and physical activity through the use of behavior change techniques. In addition, it is recommended that parents are involved in the intervention ${ }^{8}$ because of the integral role they play in the lifestyle of their child. ${ }^{9}$

Mind, Exercise, Nutrition, Do it! (MEND) is a familybased combined lifestyle group intervention for children with overweight and obesity in the community, which was originally developed in the United Kingdom. It has been shown to be effective in reducing weight status and emotional distress, while simultaneously increasing the selfesteem and body esteem of children aged between 7 and 13 years. ${ }^{10-13}$ Given these promising effects, and in light of the absence of any such evidence-based intervention in the Netherlands, the Dutch Ministry of Health financed the project Care for Obesity (C4O) to (among other things) adapt and subsequently pilot this intervention within 11 municipalities, with the express aim of implementing it in cities across the Netherlands. The adapted intervention is called LEFF (Lifestyle, Energy, Fun, and Friends).

This study aims to assess the changes in generic HRQOL, weight-specific HRQOL, and the weight status of children with overweight and obesity aged between 7 and 13 years after engaging in a 10 -week LEFF intervention, under real-world conditions. The hypothesis is that, in concordance with the MEND results, participation in the intervention will result in significant improvement in both HRQOL and weight status.

\section{Method}

\section{Study Design}

The data that were collected during both the pilot period (2014) and the first four rounds of implementation (20152016) of the intervention were used in the study. In total, the 10 pilot and 34 implementation intervention groups were conducted in 16 locations (e.g., a local community center or a school) in 11 municipalities across the Netherlands. All 44 of these groups were included in the study. Our preference was for 8-12 families to participate in each group; however, in practice, there was often some degree of variation in the group sizes, depending on the local circumstances. The intervention occurred in districts where the municipality had implemented an integrated approach to tackling overweight and obesity. These were often disadvantaged neighborhoods.

\section{The LEFF Intervention}

Over the course of the 10-week intervention, in 2-hour long biweekly sessions, families learned from a coach about how to live a healthier lifestyle through covering the themes nutrition, physical activity, and behavior. Improving families' own knowledge, attitudes, social support, and selfefficacy was the principal focus of these sessions. The first hour of each session was attended by children and caregivers together, whereas in the second hour children engaged in physical activity while their caregivers discussed parenting in relation to predefined topics (such as healthy habits, role modeling, and setting goals). Although the coaches did not have a specific (para)medical background or educational level, they received a LEFF training to be able to effectively deliver the intervention. Coaches did have prior experience in working with groups, strong communication skills, and were able to motivate their respective groups. It was preferable for the nutrition and behavior coaches to have a background in nutrition, health promotion, or behavior change, whereas the physical activity coaches had a background in physical education or sports. It was preferable that the coaches either originated from or were familiar with the local community in which the intervention took place.

The coaches' 2-day training course mainly focused on how to effectively facilitate discussions and communicate in a positive tone of voice. The core principles of the intervention and its theoretical grounding in nutrition, physical activity, and behavior were also taught. The training culminated in a test, which the coaches were required to pass to start LEFF. Within the training, role-play scenarios were performed to practice the theory they had learned. The trainer was a former coach, and a current physical activity coach was also present.

\section{Participants}

Participants were mainly referred by the municipal public health services that perform regular health checkups, as well as by schools and other referrers (e.g., family coaches, family managers, LEFF team members, and parent-child counselors). Local LEFF coordinators used information sessions, flyers, and social media as recruitment strategies to inform both referrers and families about LEFF. The child and their caregiver were eligible to participate when the child had overweight or obesity (in accordance with the cutoff scores of Cole and Lobstein ${ }^{14}$ ) if the child was aged between 7 and 13 years, if the child attended primary school, if both the caregiver and child expressed an intention to attend all sessions, and if the caregiver had sufficient mastery of the Dutch language to be able to participate in group conversations. Participants were excluded if they had medical, physical, psychological, learning, and/or behavioral problems, as assessed by the referring clinician, which could potentially hinder their participation in the intervention. In total, 340 children and their caregivers met the inclusion criteria and were thus included in this study. Table 1 provides an overview of the baseline characteristics of the children and the caregivers who were included in the study. The table also describes the characteristics of those children who had a high attendance rate $(>75 \%$ of the sessions). Furthermore, although most of the children were born in the Netherlands, $73 \%$ of the children had a non-Dutch ethnicity.

Before the intervention, one participating caregiver signed an informed consent form for the following measurements: the Healthy Growth Check 1 (HGC1), which took place during session 2 and provided the baseline measurement, and the Healthy Growth Check 2 (HGC2), which took place at 
Table I. Baseline Characteristics of Children and Their Participating Caregivers

Children with a high attendance rate $(\mathrm{N}=179)$

\begin{tabular}{|c|c|c|c|c|c|c|c|c|}
\hline & & \\
\hline & $\mathbf{N}(\%)$ & $M(S D)$ & Min & Max & $\mathbf{N}(\%)$ & $M(S D)$ & Min & Max \\
\hline \multicolumn{9}{|l|}{ Children } \\
\hline Age & $172(96)$ & $9.93(1.49)$ & 7.10 & 12.92 & $314(92)$ & $10.04(1.44)$ & 7.10 & 12.92 \\
\hline Generic QoL & 170 & $78.92(14.00)$ & 32.61 & 100 & $303(89)$ & $78.96(13.62)$ & 36.60 & 100 \\
\hline Weight-specific QoL & 164 & $87.26(12.54)$ & 41.85 & 100 & $289(85)$ & 86.04 (12.99) & 41.85 & 100 \\
\hline SDS-BMI & |7| (96) & $2.35(0.5 \mathrm{I})$ & 1.19 & 3.50 & 308 (9l.9) & $2.37(0.50)$ & 1.00 & 3.59 \\
\hline \multicolumn{9}{|l|}{ Gender } \\
\hline Male & $70(40)$ & & & & $126(38)$ & & & \\
\hline Female & $103(60)$ & & & & $204(62)$ & & & \\
\hline \multicolumn{9}{|l|}{ Weight status } \\
\hline Overweight & 71 (44) & & & & $119(39)$ & & & \\
\hline Obesity & $65(40)$ & & & & $133(44)$ & & & \\
\hline Severe obesity & $27(17)$ & & & & $51(17)$ & & & \\
\hline \multicolumn{9}{|l|}{ Ethnicity ${ }^{\mathrm{a}}$} \\
\hline Dutch & $44(27)$ & & & & $79(27)$ & & & \\
\hline Turkish & $24(15)$ & & & & $37(12)$ & & & \\
\hline Moroccan & $52(32)$ & & & & $83(28)$ & & & \\
\hline Otherb & $43(26)$ & & & & $100(34)$ & & & \\
\hline \multicolumn{9}{|l|}{ Country of birth } \\
\hline The Netherlands & $163(96)$ & & & & $273(8 \mid .5)$ & & & \\
\hline Turkey & I $(0.6)$ & & & & $\mathrm{I}(0.1)$ & & & \\
\hline Morocco & I $(0.6)$ & & & & $\mathrm{I}(0.1)$ & & & \\
\hline Other ${ }^{c}$ & $5(3)$ & & & & $18(5.4)$ & & & \\
\hline \multicolumn{9}{|l|}{ Participating caregivers } \\
\hline Age & $83(46)$ & $41.50(6.19)$ & 26.50 & 60.20 & $136(40)$ & $41,82(6.78)$ & 26.50 & 64.50 \\
\hline \multicolumn{9}{|l|}{ Weight status } \\
\hline Healthy weight & $24(16)$ & & & & $42(15)$ & & & \\
\hline Overweight & $37(25)$ & & & & $73(26)$ & & & \\
\hline Obesity & $44(30)$ & & & & 81 (29) & & & \\
\hline Severe obesity & 43 (29) & & & & $82(30)$ & & & \\
\hline \multicolumn{9}{|l|}{ Level of education ${ }^{d}$} \\
\hline Low & $60(39)$ & & & & $106(39)$ & & & \\
\hline Medium & $65(42)$ & & & & 115 (42) & & & \\
\hline High & $28(18)$ & & & & $50(18)$ & & & \\
\hline
\end{tabular}

${ }^{a}$ According to definitions of Statistics Netherlands, the native country of the parents was used to determine the ethnicity of the children. ${ }^{32}$ In the case of a non-Dutch native country of one of the parents, the non-Dutch native country was leading in determining the ethnicity of the child.

bOther: Afghanistan, Algeria, Belgium, Netherlands Antilles, Aruba, Bonaire, Bulgaria, China, Curaçao, Dominican Republic, Germany, Egypt,

Ethiopia, France, Ghana, Guyana, Ireland, Indonesia, Iraq, Iran, Italy, Jamaica, Cameroon, Kenya, Kosovo, Liberia, Macedonia, Nigeria, Pakistan,

Palestine, Poland, Rwanda, Senegal, Serbia, Slovakia, Somalia, Suriname, Syria, Venezuela, and Sweden.

'Other: Bulgaria, Germany, Egypt, Ethiopia, France, Macedonia, Pakistan, Poland, Spain, and Syria.

${ }^{\mathrm{d}}$ The highest level of education of the parents was used. Low education (I) contained primary school and lower general secondary education. Medium education (2) contained intermediate vocational education, higher general secondary education and preuniversity education. High education (3) contained higher vocational education and university education. ${ }^{33,34}$

QoL, quality of life; SD/SDS, standard deviation. 
the end of the 10-week intervention (during session 19). In HGC1 and HCG2, children's weight, height, and generic and weight-specific HRQOL were measured.

\section{Outcome Measurements}

Generic HRQOL. Generic HRQOL was measured through the PedsQL 4.0 questionnaire that was completed on paper by the children. The validated Dutch translation was used. ${ }^{15}$ The PedsQL 4.0 comprises 23 items distributed over four dimensions: Physical Functioning, Emotional Functioning, Social Functioning, and School Functioning. ${ }^{16}$ The scores were subsequently transformed into a scale, in which 0 represented low generic HRQOL and 100 represented high generic HRQOL. The original study of the PedsQL 4.0 indicated strong internal consistency (Cronbach's $\alpha=0.89$ ) and construct validity. ${ }^{16}$ In this study, the reliability was high for both measurements (T0 Cronbach's $\alpha=0.87$; T1 Cronbach's $\alpha=0.90$ ).

Weight-specific HRQOL. Weight-specific HRQOL was measured through the impact of IWQOL-KIDS parent form and was completed by the participating caregivers on paper. The validated Dutch translation was used. ${ }^{17}$ The IWQOLKIDS is a questionnaire comprising 27 items divided over four dimensions: physical comfort, body esteem, social life, and family relations. ${ }^{18}$ The scores were transformed into a scale, in which " 0 " represented low weight-specific HRQOL and "100" represented high weight-specific HRQOL. The original study indicated strong internal consistency (Cronbach's $\alpha=0.96$ ) and construct validity. ${ }^{18}$ In this study, the reliability was high for both measurements (T0 Cronbach's $\alpha=0.89$; T1 Cronbach's $\alpha=0.93$ ).

Standard deviation of BMI. Weight and height were measured by the coaches following standardized procedures. Coaches were trained and followed a protocol: Standing height was measured to the nearest $0.1 \mathrm{~cm}$, children were weighed without shoes, and weight was rounded to the nearest $0.1 \mathrm{~kg}$. Measurement taking was also practiced in the training provided to coaches. Standard deviation (SDS) of BMI was calculated using the fourth Dutch nationwide growth study as a reference. ${ }^{19}$ Furthermore, weight status (healthy weight, overweight, obesity, and severe obesity) was based on the international BMI cutoff points developed by Cole and Lobstein. ${ }^{14}$

\section{Statistical Analyses}

The analyses were executed with the use of IBM SPSS statistics 23 and R (v 3.1.2), using the lme4 package. Missing value analyses were computed on outcome variables while taking age, gender, ethnicity, parental education, and parental BMI into account. In addition, Spearman rank correlations were computed between the three outcome variables.

Main analyses. Both generic and weight-specific HRQOL were not normally distributed. Therefore, nonparametric tests were carried out. Missing data were han- dled by imputing the outcome 100 times. To assess the change in HRQOL after the 10-week intervention, Wilcoxon signed-rank and Mann-Whitney $U$ tests were conducted. To assess the change in SDS-BMI, a paired $t$-test was used. Analyses were also conducted separately for children with complete data.

Additional analyses. To explore the variation in the changes in HRQOL further, two groups were formed: the first comprised children who scored $<75$ at the start (around the lowest 33.3\% of scores), whereas the second comprised children who scored $>75$ at the start. For both groups, a Wilcoxon signed-rank test was conducted to assess the changes in HRQOL. Next, multilevel modeling was used to assess the changes in HRQOL and SDS-BMI, while simultaneously taking the nested nature of the data into account. More specifically, the first level was defined as the repeated measures, the second level was defined as the individuals, and the third level was defined as the locations.

\section{Results}

\section{Preliminary Results}

A total of 483 children and their caregivers were assessed for eligibility and agreed to participate in this study. Of these children, 25 were under the age of 7 and 10 were above the age of 13 . Twenty children were deemed to be a healthy weight in accordance with the international cutoff points of Cole and Lobstein. ${ }^{14}$ Therefore, these 55 children were excluded from this study. Moreover, 88 children who signed up for the study but failed to show up (nonstarters) were also excluded.

Of those children for whom we had attendance data $(N=259,76 \%), 179(57 \%)$ had a high attendance rate ( $>75 \%$ presence at the group sessions). The mean attendance rate was $73.7 \%$. In addition, $84 \%$ of the families were present for more than half of the sessions.

For $10 \%$ of the children SDS-BMI was missing at T0, whereas for $28 \%$ of the children this was missing at T1. In addition, $11 \%$ of the generic HRQOL was missing at T0, whereas $28 \%$ was missing at T1. Regarding weightspecific HRQOL, $15 \%$ was missing at $\mathrm{T} 0$ and $35 \%$ at $\mathrm{T} 1$, respectively. According to a missing value analysis, the missing data were missing at random.

Furthermore, Spearman rank correlations indicated that generic HRQOL and weight-specific HRQOL were significantly associated with each other, both at the baseline measurement and after the 10 -week intervention $\left(0.37<r_{\mathrm{s}}\right.$ $<0.43, p<0.01)$. Similarly, the change in generic HRQOL was positively associated with the change in weight-specific HRQOL $\left(r_{\mathrm{s}}=0.19, p<0.01\right)$. Furthermore, generic HRQOL scores at both the baseline measurement and the 10-week measurement were not associated with SDS-BMI at either the baseline or 10 -week measurements $\left(-0.05<r_{\mathrm{s}}<-0.01\right.$, $p=$ n.s.), and neither was the change in generic HRQOL associated with the change in SDS-BMI $\left(r_{\mathrm{s}}=0.06, p=0.39\right)$. 
Finally, weight-specific HRQOL (both at the baseline measurement and after the 10-week intervention) was significantly associated with SDS-BMI $\left(-0.30<r_{\mathrm{s}}<-0.26, p<0.01\right)$, whereas the change in weight-specific HRQOL and change in SDS-BMI was not significantly associated $\left(r_{\mathrm{s}}=0.12, p=0.13\right)$.

\section{Main Analyses}

First, as shown in Table 2, generic HRQOL was statistically significantly higher after the 10 -week intervention $(Z=-3.58, p<0.001, r=-0.25)$. The baseline median of generic HRQOL was 80.78 , whereas the median after the 10 -week intervention was 83.70 . The average change in generic HRQOL was 1.97, 95\% confidence interval [CI, 0.513.42]. Similarly, weight-specific HRQOL improved significantly after the 10 -week intervention $(Z=-4.83, p<0.001$, $r=-0.34)$. The baseline median of weight-specific HRQOL was 86.04 , whereas the median after the 10 -week intervention was 88.01 . The average change in weight-specific HRQOL was $2.89,95 \%$ CI [1.45-4.33]. In addition, the scores on all subscales of generic and weight-specific HRQOL, with the exception of school functioning, improved.

SDS-BMI $\left(M_{\mathrm{T} 0}=2.37, S D_{\mathrm{T} 0}=0.51\right)$ was significantly lower after the 10-week intervention $\left(M_{\mathrm{T} 1}=2.23, S D_{\mathrm{T} 1}=\right.$ $0.57, t[1194]=10,45, p<0.001, d=0.21)$. The average change in SDS-BMI was $-0.13,95 \%$ CI $[-0.15$ to -0.10$]$. Results were similar in the subgroup of children with complete data.

\section{Additional Analyses}

Low baseline HRQOL. An explorative overview of children who scored lower $(<75)$ on the total scale or subscales of HRQOL before the intervention compared with children who scored higher $(\geq 75)$ before the intervention is presented in Table 3. Overall, children who had a low HRQOL before the intervention underwent a greater improvement in their HRQOL. This was the case for both generic and weight-specific HRQOL, as well as for total scores and scores on the subscales.

Multilevel model. The results of the multilevel model showed that the three-level model (measures/individuals/ locations) was not a better fit than the two-level model (measures/individuals) in terms of explaining the differences in generic HRQOL (Intraclass Correlation Coefficients: $\mathrm{ICC}_{\text {subjects }}=0.66, \mathrm{ICC}_{\text {location }}=0.01, \chi^{2}=0.26, \mathrm{df}=1$, $p>0.05$ ), nor in terms of explaining the differences in weight-specific HRQOL $\left(\mathrm{ICC}_{\text {subjects }}=0.67, \mathrm{ICC}_{\text {location }}=0.02\right.$, $\left.\chi^{2}=0.75, \mathrm{df}=1, p>0.05\right)$. In a similar vein to the $t$-tests, generic HRQOL $\left(B_{\text {Time }}=2.03, \mathrm{SE}_{\text {Time }}=0.72, p<0.01\right)$ and weight-specific HRQOL $\quad\left(B_{\text {Time }}=2.57, \quad \mathrm{SE}_{\text {Time }}=0.68\right.$, $p<0.001)$ improved after the 10 -week intervention. In contrast to HRQOL, the three-level model was a better fit in terms of explaining the differences in SDS-BMI $\left(B_{\text {Time }}=\right.$ $\left.-0.14, \mathrm{SE}_{\text {Time }}=0.01, p<0.001, \chi^{2}=5.02, \mathrm{df}=1, p<0.05\right)$. The variance attributable to the locations was $5 \%$, whereas the variance attributable to the subject level was $92 \%$. In summary, all outcome measures improved after participating in the 10-week intervention, even when controlling for the nested nature of the data, whereas locations were able to explain some error variance in SDS-BMI, but not for generic and weight-specific HRQOL.

\section{Discussion}

The aim of this study was to determine the change in HRQOL and weight status of children with overweight or obesity aged between 7 and 13 years taking part in the LEFF

Table 2. Changes in Health-Related Quality of Life

\begin{tabular}{|c|c|c|c|c|c|c|c|c|c|}
\hline & \multicolumn{4}{|c|}{ TO } & \multicolumn{4}{|c|}{ TI } & \multirow{2}{*}{$p$} \\
\hline & Mean & Median & 25th p & 75th p & Mean & Median & 25th p & 75th p & \\
\hline \multicolumn{10}{|l|}{ Generic HRQOL } \\
\hline Total & 78.55 & 80.78 & 70.83 & 89.13 & 80.35 & 83.70 & 72.75 & 91.20 & $<0.01$ \\
\hline Physical & 80.96 & 84.38 & 71.88 & 93.75 & 82.94 & 75.00 & 87.50 & 93.75 & $<0.01$ \\
\hline Emotional & 74.74 & 80.00 & 60.00 & 90.00 & 77.28 & 80.00 & 65.00 & 95.00 & $<0.05$ \\
\hline Social & 82.06 & 86.25 & 75.00 & 100.00 & 84.15 & 90.00 & 75.00 & 100.00 & $<0.05$ \\
\hline School & 76.98 & 80.00 & 70.00 & 90.00 & 77.78 & 80.00 & 65.00 & 90.00 & n.s. \\
\hline \multicolumn{10}{|c|}{ Weight-specific HRQOL } \\
\hline Total & 86.04 & 91.67 & 80.09 & 97.22 & 88.01 & 93.52 & 82.87 & 98.15 & $<0.01$ \\
\hline Physical comfort & 87.53 & 91.67 & 79.17 & 100.00 & 88.75 & 95.83 & 79.17 & 100.00 & $<0.05$ \\
\hline Body esteem & 79.67 & 86.11 & 66.67 & 94.44 & 83.37 & 88.89 & 75.00 & 97.22 & $<0.01$ \\
\hline Social & 88.01 & 95.83 & 79.17 & 95.83 & 89.65 & 100.00 & 83.33 & 100.00 & $<0.05$ \\
\hline Family & 94.47 & 100.00 & 91.67 & 100.00 & 95.89 & 100.00 & 95.83 & 100.00 & $<0.05$ \\
\hline
\end{tabular}

HRQOL, health-related quality of life; n.s., not significant. 


\section{Table 3. Low Baseline Level versus High Baseline Level in Quality of Life} and the Changes in Quality of Life

\begin{tabular}{|c|c|c|c|c|c|c|c|c|c|c|c|}
\hline & \multirow[b]{2}{*}{$\mathbf{N}$} & \multicolumn{4}{|c|}{ TO } & \multicolumn{4}{|c|}{ TI } & \multirow{2}{*}{ Change } & \multirow{2}{*}{$p$} \\
\hline & & Mean & Median & 25th $p$ & 75th $p$ & Mean & Median & 25th p & 75th $\mathrm{p}$ & & \\
\hline \multicolumn{12}{|c|}{ Generic HRQOL } \\
\hline Low start & 101 & 63.22 & 67.39 & 55.43 & 71.04 & 70.65 & 70.65 & 63.04 & 79.35 & + & $<0.01$ \\
\hline $\begin{array}{l}\text { High start } \\
\text { Physical }\end{array}$ & 202 & 86.84 & 85.86 & 80.75 & 92.39 & 86.59 & 88.04 & 81.52 & 93.47 & $=$ & n.s. \\
\hline Low start & 103 & 63.94 & 67.86 & 56.25 & 71.88 & 72.86 & 75.00 & 65.63 & 82.81 & + & $<0.01$ \\
\hline $\begin{array}{l}\text { High start } \\
\text { Emotional }\end{array}$ & 199 & 89.76 & 90.63 & 84.38 & 96.88 & 89.10 & 93.75 & 84.38 & 96.88 & $=$ & n.s. \\
\hline Low start & 150 & 57.66 & 60.00 & 50.00 & 70.00 & 68.48 & 70.00 & 55.00 & 85.00 & + & $<0.01$ \\
\hline $\begin{array}{l}\text { High start } \\
\text { Social }\end{array}$ & 152 & 90.95 & 90.00 & 85.00 & 100.00 & 86.30 & 90.00 & 75.00 & 100.00 & - & $<0.01$ \\
\hline Low start & 93 & 58.65 & 65.00 & 45.00 & 72.50 & 71.64 & 75.00 & 60.00 & 85.00 & + & $<0.01$ \\
\hline $\begin{array}{l}\text { High start } \\
\text { School }\end{array}$ & 209 & 92.48 & 85.00 & 95.00 & 100.00 & 89.87 & 95.00 & 85.00 & 100.00 & $=$ & n.s \\
\hline Low start & 140 & 63.40 & 66.88 & 60.00 & 75.00 & 68.67 & 67.50 & 60.00 & 80.00 & + & $<0.01$ \\
\hline $\begin{array}{l}\text { High start } \\
\text { Weight-specific } \\
\text { Total }\end{array}$ & 160 & 88.67 & 90.00 & 82.19 & 95.00 & 85.67 & 90.00 & 75.00 & 95.00 & - & 0.01 \\
\hline Low start & 52 & 64.11 & 64.35 & 59.26 & 73.15 & 74.29 & 75.46 & 64.12 & 82.41 & + & $<0.01$ \\
\hline $\begin{array}{l}\text { High start } \\
\text { Physical comf }\end{array}$ & 237 & 91.58 & 93.52 & 85.19 & 97.22 & 92.30 & 95.37 & 88.89 & 99.07 & + & 0.01 \\
\hline Low start & 67 & 64.30 & 66.67 & 58.33 & 75.00 & 78.72 & 75.00 & 62.50 & 95.83 & + & $<0.01$ \\
\hline $\begin{array}{c}\text { High start } \\
\text { Body esteem }\end{array}$ & 223 & 94.50 & 100.00 & 91.67 & 100.00 & 92.83 & 100.00 & 91.67 & 100.00 & $=$ & n.s. \\
\hline Low start & 100 & 56.41 & 62.50 & 47.22 & 68.75 & 70.89 & 75.00 & 58.33 & 84.72 & + & $<0.01$ \\
\hline $\begin{array}{l}\text { High start } \\
\text { Social }\end{array}$ & 190 & 91.92 & 94.44 & 86.11 & 100.00 & 90.28 & 94.44 & 86.11 & 100.00 & $=$ & n.s. \\
\hline Low start & 64 & 62.50 & 66.67 & 55.21 & 70.83 & 74.35 & 75.00 & 62.50 & 91.67 & + & $<0.01$ \\
\hline $\begin{array}{l}\text { High start } \\
\text { Family }\end{array}$ & 229 & 95.14 & 100.00 & 91.67 & 100.00 & 93.91 & 100.00 & 91.67 & 100.00 & $=$ & n.s. \\
\hline Low start & 23 & 66.30 & 70.83 & 66.67 & 75.00 & 96.87 & 100.00 & 95.83 & 100.00 & + & $<0.01$ \\
\hline High start & 270 & 96.87 & 100.00 & 95.83 & 100.00 & 97.17 & 100.00 & 95.83 & 100.00 & $=$ & n.s. \\
\hline
\end{tabular}

Low start is a score of 75 or lower at baseline.

n.s., not significant.

intervention. The results indicated that there were favorable changes in relation to generic HRQOL, weight-specific HRQOL, and SDS-BMI after the 10-week intervention. The attendance rate was generally high. Reflections on these results are presented in the discussion as follows.
The reduction in SDS-BMI (mean change -0.13) after the 10-week intervention was in concordance with the results of the original MEND intervention, which was -0.18 during the implementation. ${ }^{11}$ Other Dutch lifestyle interventions for children produced either a similar short-term 
reduction $^{20,21}$ or no reduction in SDS-BMI. ${ }^{22}$ This small but statistically significant reduction in SDS-BMI is promising, insofar as it demonstrates the possibility of improving the weight status and health of children through conducting lifestyle intervention in this age group. ${ }^{30}$

The increase in HRQOL that was found in this study cannot be compared with the original MEND intervention, because MEND did not investigate the change in HRQOL. However, they did find an improvement in other domains closely related to HRQOL, such as physical distress and self-esteem. ${ }^{10,11}$ Other comparable lifestyle interventions for children with overweight and obesity that did evaluate HRQOL found similar results. According to a recent metaanalysis, the average mean change in generic HRQOL in the short term ( $<6$ months) was 1.73 (95\% CI $[-0.26$ to $3.73]^{23}$ ), which is slightly lower than the mean change that we found in generic HRQOL $(\Delta M=1.97)$.

Furthermore, our results are partly in line with previous studies that have indicated that HRQOL and weight status are associated with each other. ${ }^{6}$ Similar to other studies, ${ }^{18,24}$ lower weight-specific HRQOL was found in our study to be associated with higher SDS-BMI at all both baseline measurement and after 10 weeks of participation. In contrast to other studies, ${ }^{6,25}$ generic HRQOL was not found to be associated with SDS-BMI. One explanation for the lack of an association between generic HRQOL and SDS-BMI could be that in this study the variance of SDSBMI was too small. Indeed, the range in SDS-BMI was smaller in comparison with other studies because only children with overweight or obesity were studied, whereas previous studies have often included children without overweight or obesity as well. ${ }^{6}$ Another explanation for these results could be that weight-specific HRQOL provides more information about weight-related problems, whereas generic HRQOL is simply too generic. As a result, weight-specific quality of life seems to be better equipped for differentiating HRQOL in children with high and low SDS-BMI. ${ }^{26}$ This would suggest that the IWQOL is a preferable measure to use with youth with overweight and obesity. This is supported by a previous study, which indicated that the IWQOL has a greater degree of sensitivity in detecting changes in HRQOL in youth with overweight and obesity compared with the PedsQL. ${ }^{18}$

Finally, it should be noted that the average scores on both the generic HRQOL and weight-specific HRQOL were relatively high on average to begin with. This means that many of the children who took part in the study did not perceive severe HRQOL limitations as measured by the questionnaires. This may be because these children were relatively young, insofar as they were all under the age of 13, whereas previous studies indicate that HRQOL decreases during adolescence. ${ }^{6,27,28}$ Due to the high scores on HRQOL during the baseline measurement, there was a ceiling effect: children who already scored high did not have much room for improvement. This was especially the case for the subscales "Social functioning" and "Family functioning" of the IWQOL, in which the median scores were the highest scores possible. Interestingly, even though there was a ceiling effect, the children who participated in the LEFF intervention, on average, still improved significantly in terms of HRQOL.

\section{Strengths and Limitations}

This study has notable strengths and specific limitations. The combination of measuring both weight status and HRQOL can be regarded as a key strength of the study, because weight status alone provides insufficient information about a child's well-being and ability to participate in daily life. ${ }^{29}$ Measuring HRQOL can provide useful information in the assessment phase, specifically in terms of helping define the goals of the treatment, and can be used as a patient-reported outcome measure. ${ }^{26}$ Furthermore, it is interesting to assess the change in HRQOL in relation to changes in weight status, because a change in one can lead to a change in the other. ${ }^{30}$ Moreover, they can also change independently of each other. ${ }^{31}$

The main limitation of this study pertains to the study design, as we used an intervention study as opposed to conducting a randomized control trial to assess the effect of an intervention. However, LEFF is the Dutch adaptation of the original MEND intervention, which has been proven to be effective in both randomized and longitudinal examinations. ${ }^{10,12,13}$ Therefore, even though the design of the study was not necessarily optimal, the results of this study still provide relevant information. Specifically, the results are in line with the results of MEND, which suggest that this Dutch adaptation of MEND has beneficial effects for children with overweight or obesity. The long-term-outcomes of LEFF are envisaged to be in concordance with the (modest) positive long-term outcomes of MEND. ${ }^{12}$ Moreover, this study shows that it is possible to adapt MEND to the Dutch context and effectively implement this intervention across different Dutch municipalities.

The second limitation of this study is the high percentage of nonstarters. At least one-third of the children who signed up to participate did not engage in the intervention. Therefore, it is possible that there may have been a selection bias. However, the remaining sample still comprised high-risk children. For example, of all the participants, $72 \%$ had a non-Dutch ethnicity, $34 \%$ had two parents with a low educational level, whereas $60 \%$ of the children had obesity or severe obesity. In addition, the intervention has been conducted in several disadvantaged neighborhoods throughout the Netherlands.

\section{Conclusion and Implications}

In conclusion, the results of this study demonstrate that participation in the LEFF intervention was associated with improved generic HRQOL, weight-specific HRQOL, and SDS-BMI. Future studies should investigate the long-term outcomes of this intervention for children with overweight and obesity as part of an integrated care approach. Moreover, the cost-effectiveness of lifestyle interventions for children with overweight or obesity should be assessed and 
compared. All in all, this study indicates that LEFF is a promising intervention for children with overweight and obesity in the Netherlands. In addition, it provides a unique contribution to integrated care for childhood overweight and obesity in the Netherlands by providing a treatment option for the first step in the stepped care system.

\section{Ethical Approval}

This study was approved by the Medical Ethics Committee of VU University Medical Centre Amsterdam, the Netherlands. All participants provided consent to participate in the study and for their data to be included in subsequent publications.

\section{Availability of Data and Material}

The data sets analyzed in this study are not publicly available, because the authors do not have permission from the participants to share their data with other researchers. Moreover, the data include multiple potential patient identifiers, such as birthdate, place of treatment, anthropometric measures, gender, and ethnicity. However, anonymized data are available from the authors on reasonable request.

\section{Authors' Contributions}

All authors made substantial contributions to the study. E.v.d.E., J.C.S., and J.H. made contributions to the conception and design. E.v.d.E. acquired the data. All authors contributed to the analysis and interpretation of the data. E.v.d.E., R.C., and L.R.P. drafted the article. All authors were involved in critically revising the intellectual content in the article. All authors have read and approved the final article.

\section{Acknowledgments}

We acknowledge and thank Sanne Niemer for the essential work in regard to LEFF in general and this study specifically. We also acknowledge the assistance of Sophie Pulles, Denise de Kant, Gwennis Keja, Roos Keja, Corine Bruggers, Hanneke Noordam, Irene Gruintjes, the local LEFF teams, and LEFF coordinators. Furthermore, we thank the participants and their parents/caretakers for participating in this study.

\section{Funding Information}

This study was funded by the Dutch Ministry of Health, Welfare and Sport (grant number 324043), as part of the project Care for Obesity. The preparation of this article was also partly funded by the Netherlands Cardiovascular Research Initiative, which receives support from the Dutch Heart Foundation and ZonMw, CVON2016-07 LIKE.

\section{Author Disclosure Statement}

The authors J.C.S., J.H., and E.v.d.E. declare that they were involved in the process of adapting MEND (original intervention) into LEFF. The project received funding from the Dutch Ministry of Health for, among other things, the MEND license and to support this adaptation. These authors declare no other (financial) interests. With respect to the other authors (C.M.R., L.R.P., and R.C.), no competing (financial) interests exist.

\section{References}

1. Ng M, Fleming T, Robinson M, et al. Global, regional, and national prevalence of overweight and obesity in children and adults during 1980-2013: A systematic analysis for the Global Burden of Disease Study 2013. Lancet 2014;384:766-781.

2. Schonbeck $Y$, Talma $H$, van Dommelen $P$, et al. Increase in prevalence of overweight in Dutch children and adolescents: A comparison of nationwide growth studies in 1980, 1997 and 2009. PloS One 2011;6:e27608.

3. WHO. Diet, Nutrition and the Prevention of Chronic Diseases: Report of a Joint WHO/FAO Expert Consultation. WHO: Geneva, Switzerland, 2003.

4. Cornette R. The emotional impact of obesity on children. Worldviews Evid Based Nurs 2008;5:136-141.

5. Reilly JJ. Descriptive epidemiology and health consequences of childhood obesity. Best Pract Res Clin Endocrinol Metab 2005;19: 327-341.

6. Buttitta M, Iliescu C, Rousseau A, Guerrien A. Quality of life in overweight and obese children and adolescents: A literature review. Qual Life Res 2014;23:1117-1139.

7. Seidell JC, Halberstadt J, Noordam H, Niemer S. An integrated health care standard for the management and prevention of obesity in the Netherlands. Fam Pract 2012;29(Suppl 1):i153-i156.

8. Ells LJ, Rees K, Brown T, et al. Interventions for treating children and adolescents with overweight and obesity: An overview of Cochrane reviews. Int J Obes 2018;42:1823-1833.

9. Golan M, Crow S. Parents are key players in the prevention and treatment of weight-related problems. Nutr Rev 2004;62:39-50.

10. Sacher PM, Kolotourou M, Chadwick PM, et al. Randomized controlled trial of the MEND program: A family-based community intervention for childhood obesity. Obesity (Silver Spring) 2010; 18(Suppl 1):S62-S68.

11. Fagg J, Chadwick P, Cole TJ, et al. From trial to population: A study of a family-based community intervention for childhood overweight implemented at scale. Int J Obes (Lond) 2014;38: $1343-1349$

12. Kolotourou M, Radley D, Gammon C, et al. Long-term outcomes following the MEND 7-13 child weight management program. Child Obes 2015;11:325-330.

13. Sacher PM, Kolotourou M, Poupakis S, et al. Addressing childhood obesity in low-income, ethnically diverse families: Outcomes and peer effects of MEND 7-13 when delivered at scale in US communities. Int J Obes (Lond) 2019;43:91-102.

14. Cole TJ, Lobstein T. Extended international (IOTF) body mass index cut-offs for thinness, overweight and obesity. Pediatr Obes 2012;7:284-294.

15. Bastiaansen D, Koot H, Bongers I, et al. Measuring quality of life in children referred for psychiatric problems: Psychometric prop- 
erties of the PedsQL TM 4.0 generic core scales. Qual Life Res 2004;13:489-495.

16. Varni JW, Burwinkle TM, Seid M, Skarr D. The PedsQL 4.0 as a pediatric population health measure: Feasibility, reliability, and validity. Ambul Pediatr 2003;3:329-341.

17. Wouters EJM, Geenen R, Kolotkin RL, Vingerhoets AJJM. Met lichaamsgewicht samenhangende kwaliteit van leven bij adolescenten. Tijdschrift voor kindergeneeskunde 2010;78:119-125.

18. Kolotkin RL, Zeller M, Modi AC, et al. Assessing weight-related quality of life in adolescents. Obesity 2006;14:448-457.

19. Fredriks AM, van Buuren S, Burgmeijer RJ, et al. Continuing positive secular growth change in the Netherlands 1955-1997. Pediatr Res 2000;47:316-323.

20. Slinger J, Van Breda E, Brouns J, Kuipers H. Effects of a 12 week practice based lifestyle program to counteract overweight in adolescents: An intervention study. Published in Doctoral Thesis: Fit Kids, Healthy Kids, 2008, pp. 79-92.

21. de Vries S, Schokker D, Galindo Garre F, Crone M, van der Kamp H. Effectevaluatie van een multidisciplinair behandelprogramma voor jeugdigen met een overgewicht: Weet and Beweeg. Leiden, The Netherlands: TNO Kwaliteit van Leven; 2010.

22. Gerards SM, Dagnelie PC, Gubbels JS, et al. The effectiveness of lifestyle triple $\mathrm{P}$ in the Netherlands: A randomized controlled trial. PLoS One 2015;10:e122240.

23. Ligthart KA, Paulis WD, Djasmo D, et al. Effect of multidisciplinary interventions on quality of life in obese children: A systematic review and meta-analysis. Qual Life Res 2015;24:1635-1643.

24. Fallon EM, Tanofsky-Kraff M, Norman AC, et al. Health-related quality of life in overweight and nonoverweight black and white adolescents. J Pediatr 2005;147:443-450.

25. Varni JW, Limbers CA, Burwinkle TM. Impaired health-related quality of life in children and adolescents with chronic conditions: A comparative analysis of 10 disease clusters and 33 disease categories/severities utilizing the PedsQL 4.0 Generic Core Scales. Health Qual Life Outcomes 2007;5:43.

26. Noordam H, Halberstadt J, Seidell JC. Kwaliteit van leven als uitkomstmaat in de zorg voor kinderen (4-19 jaar) met obesitas. Tijdschrift voor gezondheidswetenschappen 2016;94:300-304.
27. Williams J, Wake M, Hesketh K, Maher E, Waters E. Healthrelated quality of life of overweight and obese children. JAMA 2005;293:70-76.

28. Wille N, Bullinger M, Holl R, et al. Health-related quality of life in overweight and obese youths: Results of a multicenter study. Health Qual Life Outcomes 2010;8:36.

29. Russell-Mayhew S, McVey G, Bardick A, Ireland A. Mental health, wellness, and childhood overweight/obesity. J Obes 2012; 2012:281801.

30. Griffiths LJ, Parsons TJ, Hill AJ. Self-esteem and quality of life in obese children and adolescents: A systematic review. Int J Pediatr Obes 2010;5:282-304.

31. Hoedjes M, Makkes M, Halberstadt J, et al. Health-related quality of life in children and adolescents with severe obesity after intensive lifestyle treatment and at 1-year follow-up. Obes Facts 2018;11:116-128.

32. CBS. Hoeveel allochtonen wonen er in Nederland? [How many immigrants live in the Netherlands?] Centraal Bureau van de Statistiek. 2016.

33. de Jong E, Schokker DF, Visscher TL, et al. Behavioural and sociodemographic characteristics of Dutch neighbourhoods with high prevalence of childhood obesity. Int J Pediatr Obes 2011;6:298-305.

34. Grubben BHGM, Pelsers JHM, Timmermans GLPC. Jaarboek Welvaartsverdeling 2000: Feiten en cijfers over inkomen en consumptie in Nederland. [Yearbook Wealth distribution 2000: Facts and figures about income and consumption in the Netherlands] Centraal Bureau voor de Statistiek. 2000

Address correspondence to: Emma van den Eynde, MSc Department of Pediatric Endocrinology Erasmus $M C$ University Medical Center 3015 GD Rotterdam the Netherlands

E-mail: e.vandeneynde@erasmusmc.nl 